\title{
LAS REVISTAS PEDAGÓGICAS: UNA FUENTE ÚTIL PARA LA INVESTIGACIÓN HISTÓRICA EDUCATIVA
}

\author{
Lucía Martínez Moctezuma \\ Universidad Autónoma del Estado de Morelos, México \\ luciamm@uaem.mx
}

En la colección de educación que resguarda la Universidad Autónoma del Estado de Morelos en México, se conserva un buen número de libros de texto, revistas pedagógicas y cuadernos escolares. Algunos de ellos han servido para preparar tesis de grado, ponencias, artículos y capítulos de libros, con temas tan variados como la formación del maestro, la enseñanza de las disciplinas escolares, los métodos de lectura, las influencias extranjeras y las representaciones del cuerpo infantil. Se trata de documentos ricos en información por la calidad de sus textos pero también por sus imágenes y fotografías que suponen un reto para el investigador. Por esta razón nos interesa proponer un ejercicio usando las fotografías que se publicaron en la revista pedagógica La Enseñanza Normal. Si bien hay múltiples datos en una imagen, no podemos reconstituir con ella el pasado pero sí, como lo sugiere el investigador brasileño Boris Kossoy (2001), abrir un abanico de interpretaciones con la información visual que nos da el fotógrafo quien ha seleccionado un fragmento de la realidad y la ha organizado estética e ideológicamente ${ }^{1}$. Con esta mirada, podremos crear una nueva fuente de información a partir de la interpretación iconológica que hagamos de ésta ${ }^{2}$.

\section{LAS FOTOGRAFÍAS Y SU USO EN LA INVESTIGACIÓN EDUCATIVA}

Como en el caso de los libros escolares, desconocemos el tiraje de las revistas pedagógicas aunque sabemos que estaban dirigidas a los maestros que laboraban de la escuela primaria a principios del siglo XX. La Enseñanza Normal, era una publicación periódica que editaba la Dirección General de Enseñanza Normal en el Distrito Federal en la que se divulgaba un sinfín de informaciones que los maestros debían conocer para hacer suyo el proyecto

\footnotetext{
1“A pesar de la aparente neutralidad del ojo de la cámara y de todo el verismo iconográfico, la fotografía será siempre una interpretación”. KOSSOY, Boris. Fotografía e historia. Argentina: Biblioteca de la Mirada, 2001, p. 89.

“"El análisis iconográfico tiene como meta detallar e inventariar sistemáticamente el contenido de la imagen en sus elementos icónicos formativos... (el análisis iconológico puede ayudar a entender)...la ideología (que) determina la estética de la representación: los mecanismos de producción y de recepción de la imagen..." (KOSSOY, 2001, p. 93-94).
} 
modernizador de la escuela mexicana. Se editaba en la Escuela Normal de Profesores de la ciudad de México, estaba dirigida por su director, el profesor Alberto Correa, colaboraban en ella, maestros y alumnos y tenía, como objetivo principal, colaborar en la tarea de unificar criterios en torno a la escuela mexicana, por lo menos era esto lo que se esperaba que despertaran tanto las revistas como las guías metodológicas y los boletínes de instrucción pública, que habían nacido como producto de las discusiones llevadas a cabo en el Segundo Congreso de Instrucción Pública (1890-1891).

Fotografía 1. Portada de la Revista La Enseñanza Normal, 1907.

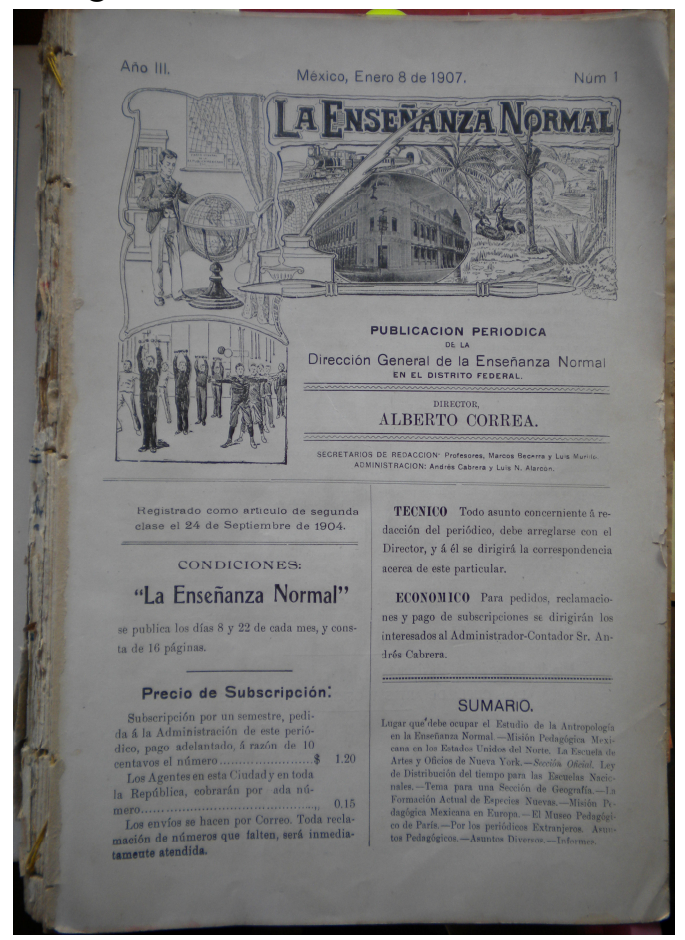

Fuente: Colección de Educación de la Universidad Autónoma del Estado de Morelos.

La Enseñanza Normal se publicaba los días 8 y 22 de cada mes, tenía alrededor de 16 páginas, con un costo de 10 centavos circuló entre 1904 y 1908 en las escuelas primarias de la ciudad de México y algunas Escuelas Normales del País. El contenido de la revista era variado. Había secciones dedicadas a la legislación escolar, novedades bibliográficas, avisos para los padres de familia, informes sobre dotaciones y donaciones a las escuelas, artículos sobre diferentes temas del saber escolar, publicidad de las casas mexicanas y extranjeras que vendían 
libros y material pedagógico, como en el caso de los pupitres de la Casa Mosler, Bowen \& Cook, Sucr., que vemos en la siguiente fotografía.

Fotografía 2. Venta de mobiliario escolar.

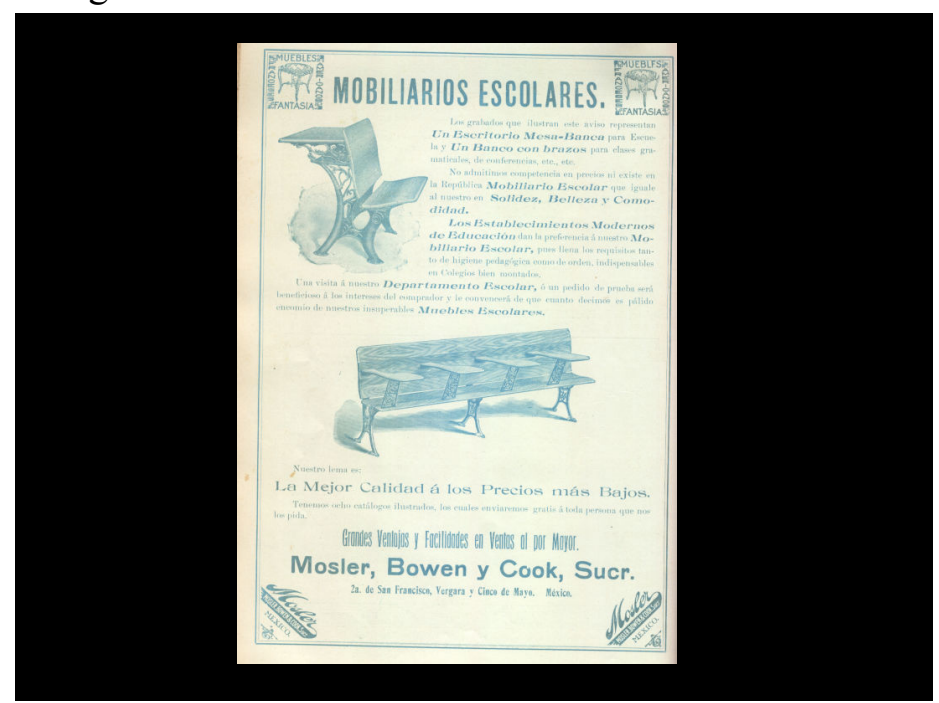

Fuente: La Enseñanza Normal, 1905, p. 2.

También había traducciones de artículos publicados en otras revistas extranjeras que permitieron a los redactores mostrar la semejanza que existía con algunas de nuestras escuelas. Esto lo vemos en el caso de las siguientes fotografías que presentan el salón de enseñanza manual de la Escuela Normal de México y las instalaciones de la sala de trabajos prácticos de la Escuela Boulle en París, Francia.

Fotografía 3. Escuela mexicana.

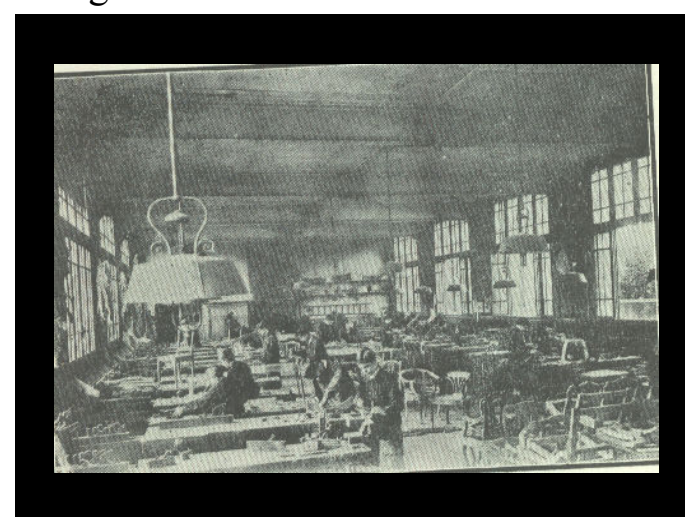

Fuente: La Enseñanza Normal, 1905, p. 200.
Fotografía 4. Escuela francesa.

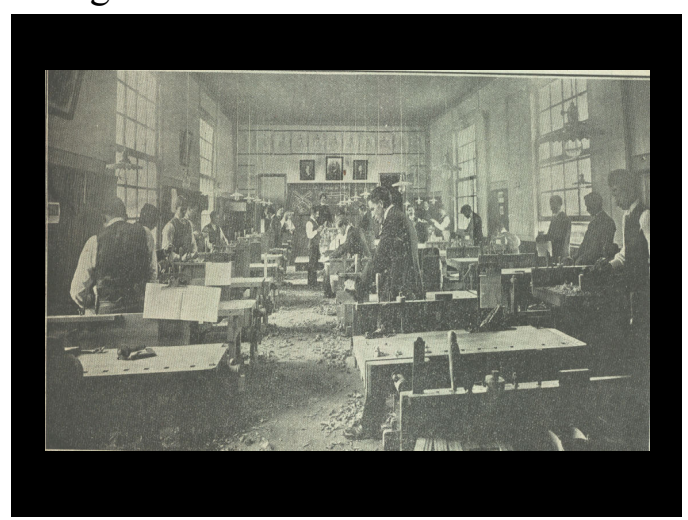

Fuente: La Enseñanza Normal, 1905, p. 2. 
Muchos de los artículos fueron escritos por los profesores que formaban parte de la élite educativa pues además de su cargo como docentes, eran responsables de impartir alguna clase en la Escuela Normal, viajaban para conocer las novedades educativas de otros lugares, discutían con sus pares en los congresos nacionales e internacionales, escribían libros y tenían cargos en la administración. En esta publicación también hubo lugar para la escritura los alumnos. Muchos de sus textos, al igual que el de los profesores, iban acompañado de fotografías. En general se trata de un registro escrito y visual que es una representación del mundo que no es real pero que nos permite acercarnos, en este caso, a un problema concreto a través de la impresión de un grupo de alumnos, futuros profesores del país, cuyos trabajos aparecieron publicados en la revista.

\section{El método intuitivo en la escuela}

El régimen del General Profirio Díaz (1877-1911) había adoptado como modelo de desarrollo el francés, fundado en una nación moderna, cosmopolita y urbana, que suponía a la nación como una construcción homogénea y occidentalizada orientada hacia el mercado internacional, reglamentada y organizada científicamente, donde los inmigrantes blancos y la inversión extranjera eran componentes claves de este concepto. En materia educativa se mostraba la imagen de un país liberal y positivista que ponía el acento en la enseñanza laica, gratuita, obligatoria. Se buscaba en el niño el desarrollo armónico de sus facultades físicas, morales, intelectuales y estéticas. Para ello se acordó adoptar el método objetivo en el proceso de aprendizaje. Con la práctica de paseos escolares, los alumnos podrían ser capaces de trazar sus propios itinerarios en una carta geográfica, evaluar las distancias y las alturas, conocer la composición de los terrenos y el funcionamiento de la maquinaria en los trabajos agrícolas.

De manera general, todo paseo escolar, era considerado como aquella salida del alumno fuera de las instalaciones escolares, bajo la dirección del maestro para cumplir un fin educativo. Si la salida era corta, para visitar un establecimiento o un punto determinado se le llamaba visita escolar. Pero si trataba de sitios distantes de la población, por un tiempo mas o menos largo y a través de un medio de transporte, se le llamaba excursión escolar. Los dos fueron considerados como los medios ideales para cultivar determinados sentimientos. En el orden físico, permitiría al alumno una libertad de acción contraria al sedentarismo y nocivo ambiente que se respiraba en la sala de clases. En el orden mental les permitiría el contacto con objetos que despertaran su curiosidad y en el orden moral, el desarrollo de un sentimiento estético. 
Fotografía 5. Visita a las instalaciones de la Hacienda de Loreto.

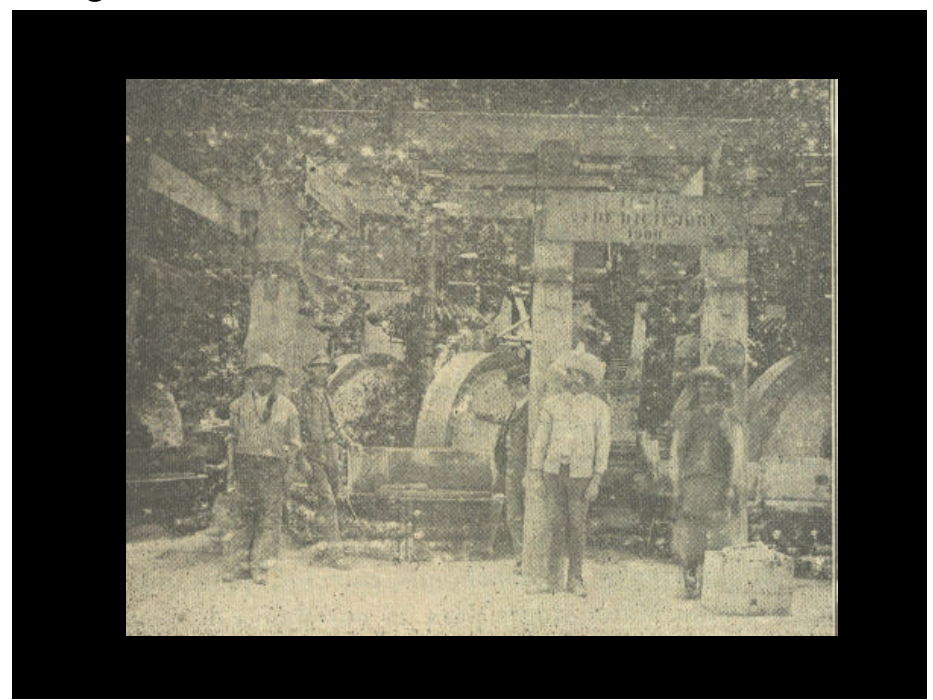

Fuente: La Enseñanza Normal, 1907, p. 31.

De acuerdo con la legislación de la época, los alumnos debían realizar mensualmente paseos al campo para conocer lugares históricos, industrias como la fábrica de seda que dirigía el francés Hipólito Chambon en Toluca, u observar el progreso del país visitando exitosas propiedades, como la Hacienda de Loreto en Pachuca, además de recoger muestras de la flora y la fauna, rocas y minerales que formarían parte del museo escolar.

Fotografía 6. Visita a la fábrica de seda en Toluca, Estado de México.

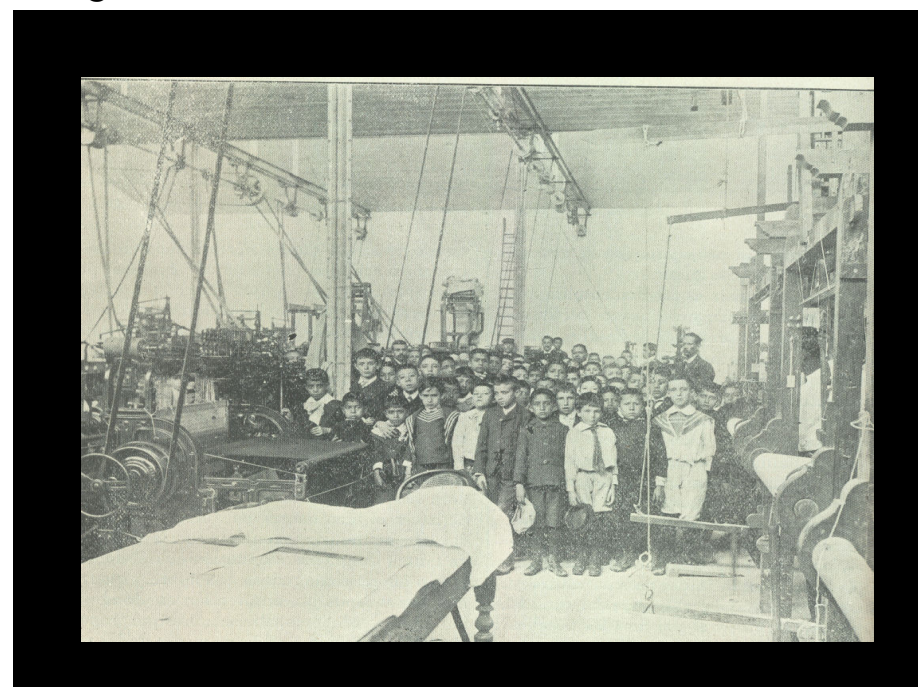

Fuente: La Enseñanza Normal, 1907, p. 131. 
En 1904, los alumnos de la Escuela Normal de la ciudad de México hicieron diferentes paseos y excursiones escolares acompañados de profesores, inspectores y editores de la revista $L a$ enseñanza Normal. Su formación se completaba con la asistencia a las conferencias pedagógicas mensuales y con la lectura de publicaciones propias al campo.

Fotografía 7. Excursión escolar en ferrocarril hacia Veracruz.

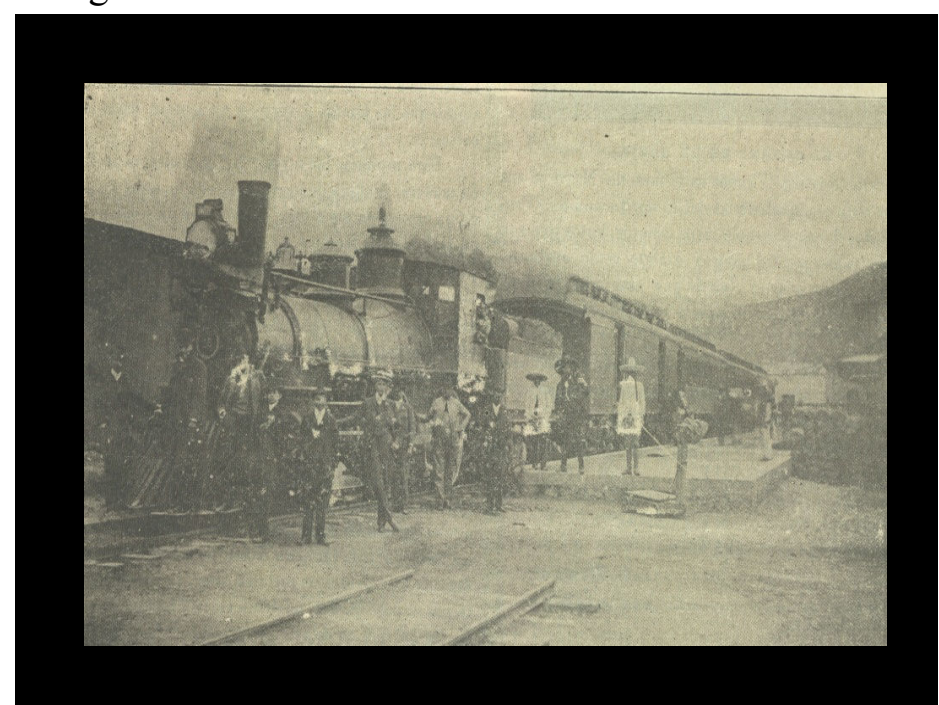

Fuente: La Enseñanza Normal, 1907, p. 35.

Los objetivos de estas visitas giraron en torno al conocimiento pedagógico de otras instituciones escolares, cumplieron fines temáticos, conocieron el progreso de ciertas industrias del país pero, también, influidos por los planteamientos higienistas y sanitarios de la época pudieron advertir "la mano arrasante del hombre" y los inconvenientes de las aglomeraciones urbanas $^{3}$.

\footnotetext{
${ }^{3}$ El artículo 17 del reglamento estipulaba que podían efectuarse excursiones escolares a lugares en que los alumnos "encontraran motivos especiales de educación o de salud..." (La Enseñanza Normal, 1907, p. 283).
} 
Fotografía 8. Visita a la Escuela Normal de Profesoras de Veracruz.

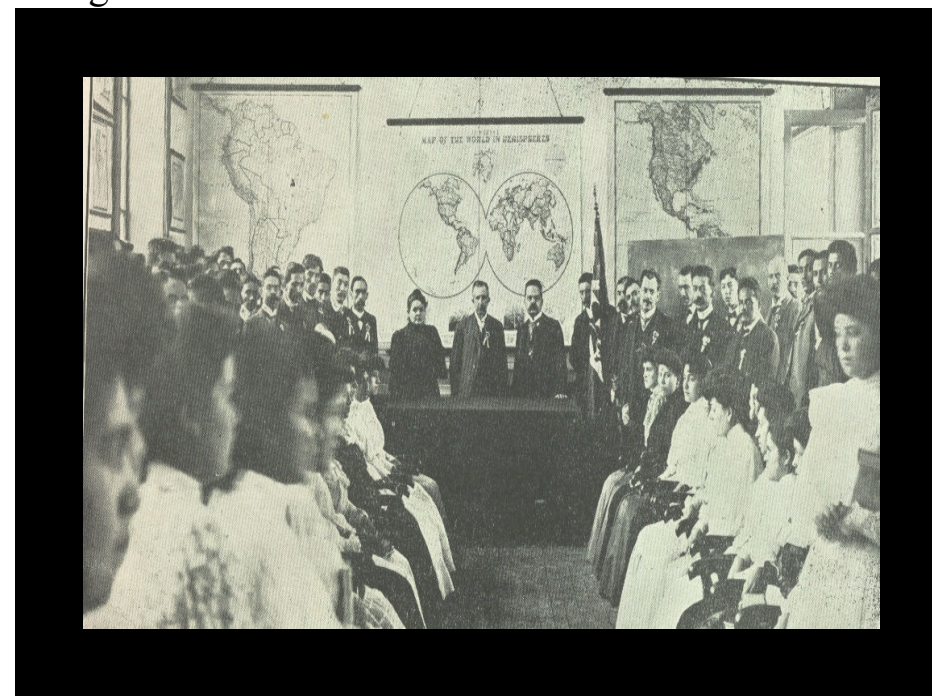

Fuente: La Enseñanza Normal, 1907, p. 14.

Uno de los destinos preferidos fue el estado de Veracruz, pues se veía con mucho aprecio, los logros educativos del profesor suizo Enrique Rébsamen en la región. Una primera excursión de tres días fue financiada por la propia entidad. La reseña del viaje dio cuenta del buen humor y de la expectación que causó el paisaje. Los viajeros conocieron el funcionamiento de vapores, corbetas y barcos-escuela, visitaron el palacio municipal, la escuela naval, las cantonales y las municipales, el Hospicio Zamora y el histórico castillo de San Juan de Ulúa que sirvió de motivo para recordar pasajes de la historia de México.

Los paseos escolares estuvieron orientados a aprender fuera del aula. Con éstos, los alumnos observaron diferencias y particularidades de cada región explorada, una gran paradoja pues la idea general de la época abogaba por la uniformidad del país, donde el discurso oficial apuntaba a conseguir que México estuviera orientado al desarrollo industrial. Sin embargo es curioso reconocer en los textos que narran los itinerarios de los viajes, que los relatores señalan claramente las diferencias entre cada región, incluso se atreven a decir que fuera de la ciudad de México también hay patria, ignorando las recomendaciones de Enrique Rébsamen quien advertía que debía "...preferirse lo que tenga colorido...pero sin caer en la exageración de querer hacer historia local y cuidándose mucho de no fomentar el espíritu del localismo". En los artículos se pone énfasis en señalar el problema de las fronteras y del regionalismo, tan perjudicial a la unidad nacional (La Enseñanza Normal, 1907, p. 15-17). 
Es claro que los viajeros que participaron en estos paseos escolares fueron alumnos privilegiados por tener acceso al conocimiento y a la experiencia, un privilegio que no sólo tuvo que ver con lo pedagógico sino también con lo económico, si consideramos que la población mexicana viajaba poco debido a las altas tarifas del transporte. Hacia 1910, un boleto en primera clase resultaba tres veces más caro que uno en diligencia. El costo de un viaje promedio de $67 \mathrm{~km}$ en segunda clase era de $\$ 1.63$ equivalente a 9.4 días de salario mínimo diario en la agricultura y dos días de trabajo para los grupos mejor remunerados. Esto explica por qué, en 1910, sólo viajó a Veracruz, una tercera parte de la población del país.Es claro que este privilegio influyó en lan perspectiva de análisis de los viajeros lo que les llevó a seleccionar fragmentos de la realidad y a elaborar un inventario parcial de lo observado.

Sin embargo, el estilo literario de sus reportes no logra ocultar el enfrentamiento que mostraron sus textos con las fotografías impresas en la publicación. Un discurso que apuntaba hacia la imposición de un modelo moderno de educación urbana y los problemas a que se enfrenta la escuela en el medio rural a causa de la inasistencia, la falta de capacidad económica para dotar a las escuelas de infraestructura o la actitud celosa de quien eran visitados. Un ejemplo de ello se muestra al comparar las fotografías de la visita que los alumnos hicieron para conocer los adelantos pedagógicos de la Escuela primaria anexa a la Normal de Toluca en el Estado de México y las fotografías que muestran el estado en que se encontraban realmente algunos de los salones de clases en el país.

Fotografía 9. Escuela primaria anexa a la Normal de Toluca en el Estado de México.

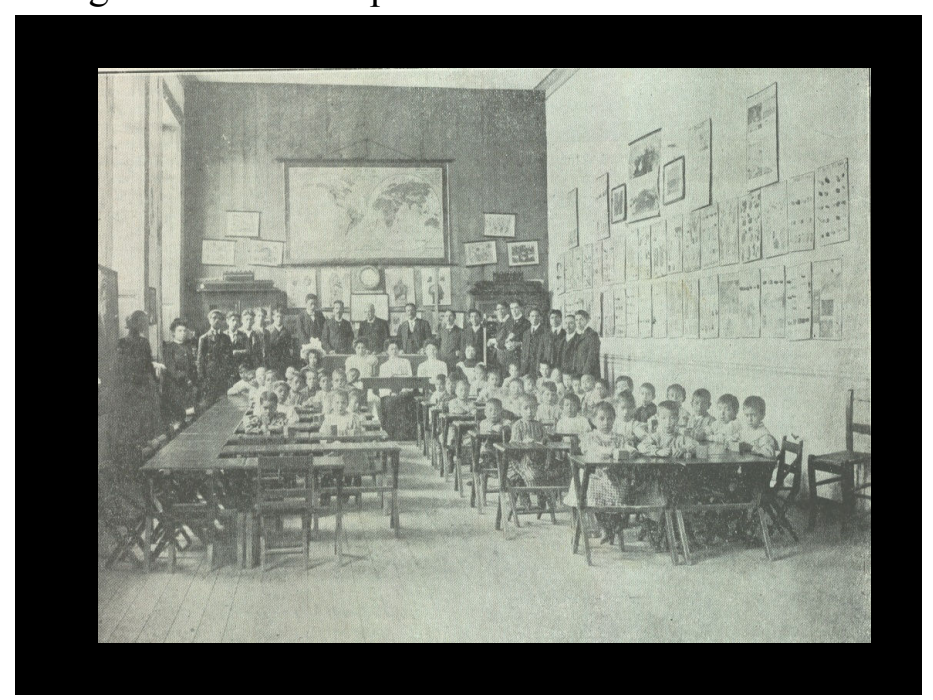

Fuente: La Enseñanza Normal, 1907, p. 275. 
El artículo que acompaña esta fotografía cumple su objetivo pues registra los elementos necesarios para hacer de esta imagen, un modelo de clase escolar, es decir, un espacio moderno donde reina la armonía y el orden. Sin embargo, en la siguiente fotografía, el objetivo de la cámara registra por accidente otra realidad. Quizá esto se deba a que el tema de la redacción no se centraba en el salón de clases sino en el interés del autor por mostrar las ventajas de realizar de manera práctica el aprendizaje de las lecciones de Metodología Aplicada a la orilla de una chinampa en Xochimilco. De cuatro fotografías que muestran el ambiente de los ejercicios topográficos, una de ellas escapa a sus intereses y muestra un salón de clases muy austero, donde el número de bancas no corresponde al número de alumnos que está presente y que por cierto no se parecen a las que se mostraban en la publicidad de la Casa Mosler de la primera fotografía que mostramos; no hay material didáctico en las paredes, que les recuerde a los alumnos la lección y la biblioteca escolar debió ser muy pobre pues los niños muestran al fotógrafo, los pocos libros con los que seguramente contaban. Es claro que en este espacio no se cumplieron los requisitos necesarios para la aplicación del método simultáneo y mucho menos los preceptos higiénicos, pues algunos niños están sucios y no llevan zapatos.

Fotografía 10. Escuela primaria en Xochimilco.

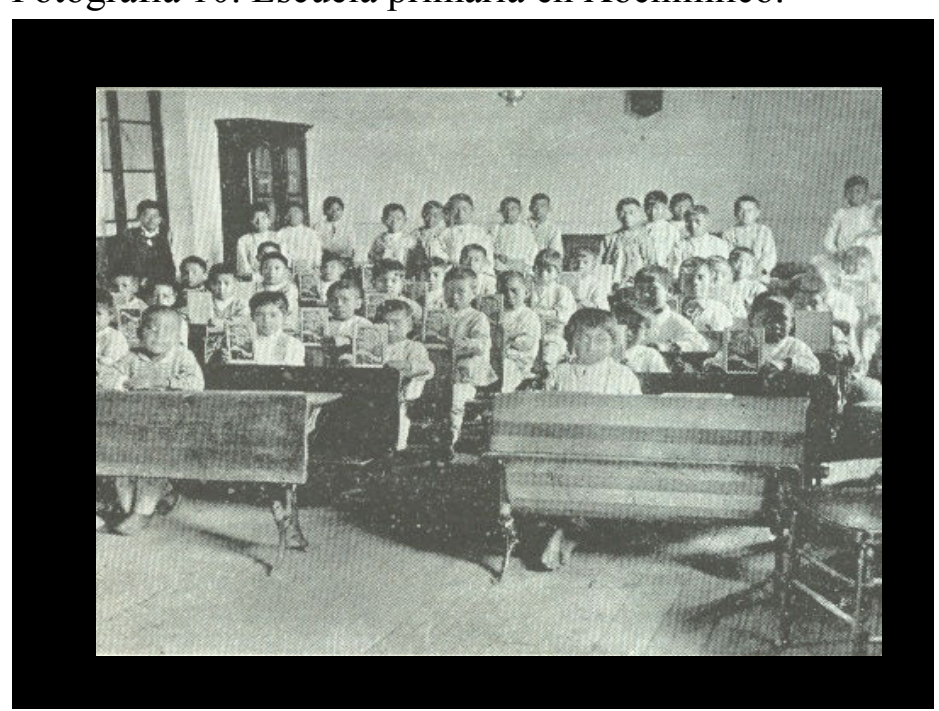

Fuente: La Enseñanza Normal, 1907, p. 325.

La misma realidad se muestra en la siguiente fotografía, cuyo objetivo principal no fue mostrar ni la pobreza ni lo inadecuado de las instalaciones para realizar los ejercicios militares que exigía el currículo. Sin embargo el objetivo de la cámara traiciona a nuestro autor y con esto, 
podemos observar la situación que vivían los alumnos de las escuelas elementales de los pueblos de Villa de Guadalupe y Tizapán, a unos cuantos kilómetros de la ciudad de México

Fotografía 11. Visita a las escuelas primarias de los pueblos de Villa de Guadalupe y Tizapán.

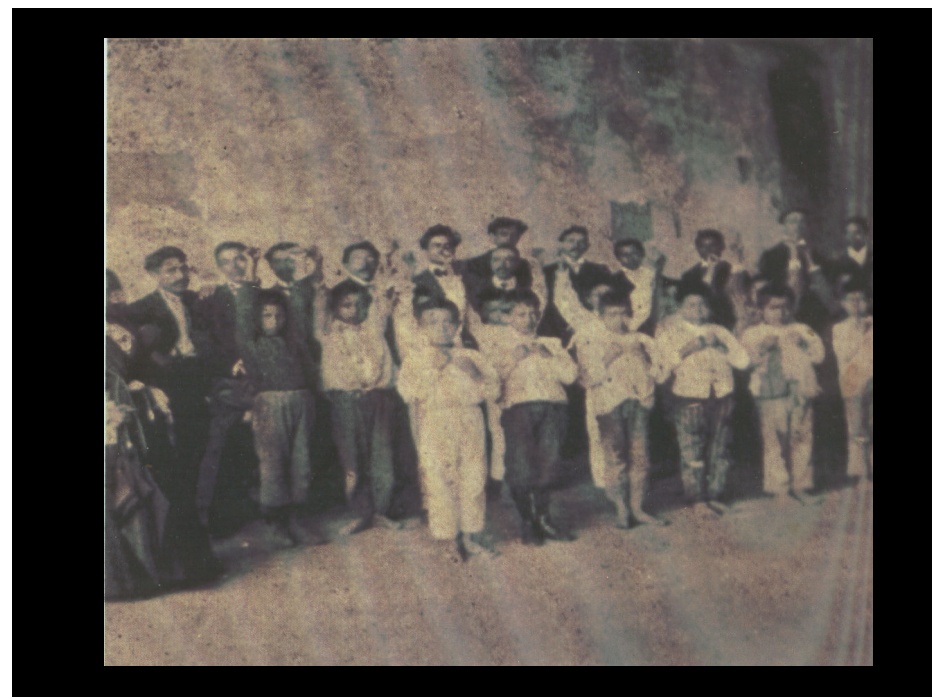

Fuente: La Enseñanza Normal, 1907, p. 328.

Aún falta mucho por conocer, pues los viajes y las excursiones escolares han tenido larga vida. Hacia 1910 fueron tema común en los discursos de los intelectuales y de los pedagogos, en los informes de los inspectores, en las reuniones académicas de los profesores, en las reseñas que los alumnos publicaron en las revistas pedagógicas y en los temas de los libros de texto. Su historia está aún por escribirse pues, en la actualidad, se sigue realizando esta práctica pedagógica en las escuelas primarias aunque los viajes sobrevivieron hasta 1984 cuando la formación normalista tomó el carácter de licenciatura. Una historia de largo alcance que, con diferentes funtes de información, como la fotografía, nos ayudará dar a conocer el impacto y la difusión de una innovación pedagógica puesta en marcha en un país rural como México.

\section{BIBLIOGRAFÍA}

KOSSOY, Boris. Fotografía e historia. Argentina: Biblioteca de la Mirada, 2001.

LA ENSEÑANZA NORMAL. Dirección General de Enseñanza Normal, Distrito Federal, Mexico, 1905, 1907. 